\title{
Association of size at birth with adolescent hormone levels, body size and age at menarche: relevance for breast cancer risk
}

\author{
S Opdahl*, 1,2, TIL Nilsen ${ }^{1,3}$, PR Romundstad', E Vanky ${ }^{4,5}$, SM Carlsen ${ }^{4,6}$ and LJ Vatten' \\ 'Department of Public Health, Faculty of Medicine, Nonwegian University of Science and Technology, Trondheim NO-7489, Norway; ${ }^{2} \emptyset$ stfold Hospital \\ Trust (Sykehuset Østfold HF), Fredrikstad NO- 1603, Norway; ${ }^{3}$ Human Movement Science Programme, Faculty of Social Sciences and Technology \\ Management, Nonwegian University of Science and Technology, Trondheim NO-749I, Nonway; ${ }^{4}$ Department of Laboratory Medicine, Children's and \\ Women's Health, Faculty of Medicine, Nonwegian University of Science and Technology, Trondheim NO-749I, Norway; ${ }^{5}$ Department of Obstetrics and \\ Gynecology, Trondheim University Hospital (St Olav's Hospital), Olav Kyrres gate 17, Trondheim NO-7006, Nonway; ${ }^{6}$ Department of Endocrinology, \\ Trondheim University Hospital (St Olav's Hospital), Olav Kyrres gate 17, Trondheim NO-7006, Norway
}

\begin{abstract}
Birth size has been positively associated with age at menarche and height in adolescence and adulthood, but the relevant biological mechanisms remain unclear. Among 262 Norwegian term-born singleton girls, birth size measures (weight, length, ponderal index, head circumference and subscapular skin-fold thickness) were analysed in relation to adolescent hormone levels (oestradiol, prolactin, dehydroepiandrosterone sulphate, androstenedione and free testosterone index), age at menarche and adolescent (ages I2.7-15.5 years) and body size (height, weight, body mass index and waist-to-hip ratio) using survival analysis and general linear modelling. The results were adjusted for gestational age at birth, age and menarcheal status at measurement in adolescence and maternal age at menarche. Birth weight, birth length and head circumference were positively associated with adolescent weight and height, and small birth size was associated with earlier age at menarche. Subscapular skin-fold thickness at birth was not associated with adolescent body size, but low fold-thickness was associated with earlier age at menarche. Measures of birth size were inversely related to circulating levels of dehydroepiandrosterone sulphate in adolescence, but there was no clear association with other hormones. These results suggest that physical and sexual development in puberty and adolescence is influenced by prenatal factors, and in combination, these factors may influence health and disease later in life.
\end{abstract}

British Journal of Cancer (2008) 99, 201 -206. doi: I0.1038/sj.bjc.6604449 www.bjcancer.com

Published online I July 2008

(C) 2008 Cancer Research UK

Keywords: size at birth; age at menarche; anthropometry; sex steroids; breast cancer risk

The hypothesis that breast cancer (BC) may originate in utero (Trichopoulos, 1990) has stimulated studies of birth size in relation to risk factors for BC (Okasha et al, 2003). Birth size is an indicator of foetal growth and may reflect intrauterine exposure to oestrogen, the key factor that was originally proposed to explain a possible association between intrauterine factors and adult BC (Trichopoulos, 1990). Studies have shown that relatively large birth size is associated with later age at menarche (Adair, 2001; Sloboda et al, 2007) and taller body height, both in adolescence (Pietiläinen et al, 2001; Romundstad et al, 2003) and in adulthood (Loos et al, 2002). Adult tallness is associated with higher BC risk, and the positive association between birth size and body height suggests that longitudinal growth in childhood and adolescence may be important determinants for subsequent BC (Michels and Willett, 2004). Birth size has also been inversely related to adrenal androgen production during childhood (Ong et al, 2004) and adolescence (Ibanez et al, 1999). Adult levels of both adrenal and gonadal androgens have been associated with $\mathrm{BC}$ risk (Kaaks et al, 2005a, b). The fact that small birth size is associated with earlier

*Correspondence: Dr S Opdahl, Sykehuset Østfold HF, Fredrikstad NO1603, Norway; E-mail: signe.opdahl@gmail.com

Revised 2 May 2008; accepted 12 May 2008; published online I July 2008 age at menarche and higher circulating levels of adrenal androgens cannot be easily reconciled with known BC risk factors, as small birth size may be related to reduced risk, and both early age at menarche and androgens are expected to increase risk.

We have examined the relation between birth size characteristics and potential BC risk factors (ESHRE Capri Workshop Group, 2004), and specifically the association with age at menarche and height and weight in adolescence, as well as with circulating levels of prolactin, androgens and oestradiol.

\section{MATERIALS AND METHODS}

The study is based on the Norwegian part of an international study among pregnant women in 1985-1986, described in detail elsewhere (Bakketeig et al, 1993). Briefly, Caucasian women with one or two singleton births were included. Of these, two groups were followed in detail throughout pregnancy and their children extensively examined at birth, one of a $10 \%$ random sample $(n=561)$ of all women; the other group of women with one or more of the following risk factors for giving birth to a small birth size for gestational age child (SGA, i.e., in the 10\% lowest birth weights for known gestational age): a previous low-birth-weight child or perinatal death, cigarette smoking at conception, 
pre-pregnancy weight below $50 \mathrm{~kg}$, chronic renal disorder or hypertension $(n=1384)$.

In 2001-2002, girls born in the original study were invited to a follow-up examination in adolescence. Among a total of 523 invited girls, 146 were excluded because they were not born at term (before week 37 or after week 42) or because exact gestational age was missing. In addition, 39 girls were excluded either because they had died $(n=5)$, were reluctant to participate $(n=8)$ or gave practical reasons $(n=26)$. Of the remaining 338 invited girls, 262 attended the follow-up examination (77.6\%). Mean age at examination in adolescence was 14.0 years (range 12.7-15.5 years). The examination included anthropometric measurements, serum samples and a questionnaire related to health and life style factors, pubertal development and menstrual status. The study was approved by the Regional Committee for Medical Research Ethics and by the Norwegian Data Inspectorate.

Birth size measurements included length (crown to heel, to the nearest half, $\mathrm{cm}$ ), weight (in g), ponderal index (weight/length ${ }^{3}$, in $\mathrm{g} \mathrm{cm}^{-3}$ ), head circumference (in $\mathrm{mm}$ ) and subscapular skin-fold thickness (10th of a millimetre after $60 \mathrm{~s}$ using a Harpenden calliper, placed below the inferior angle of the left scapula). Each measure was categorised into three groups of similar size (tertiles). Information on maternal age at menarche (years) and gestational age at delivery (days) was collected at birth.

Birth size measurements were analysed in relation to the measures of adolescent body size (height, weight, body mass index (BMI) and waist-to-hip ratio) age at menarche and to adolescent levels of oestradiol, prolactin, dehydroepiandrosterone sulphate (DHEAS), androstenedione and also free testosterone index (FTI) calculated as (total testosterone/SHBG) $\times 100$. Analyses of DHEAS and prolactin were carried out in all girls, regardless of menstrual status, but for oestradiol, androstenedione and FTI were restricted to those in the follicular phase of their menstrual cycle at examination (i.e., if the first day of her last menstruation was no more than 12 days before). We excluded six girls who had blood levels of $\mathrm{LH}$ higher than $10.0 \mathrm{Ul}^{-1}$ and/or 17-OH-progesterone higher than $10.0 \mathrm{nmoll}^{-1}$, and two girls with abnormally high levels of progesterone, leaving 62 girls for these hormone-related analyses.

Testosterone and androstenedione levels were measured by a double antibody technique on an Elecsys 2010 analyser (Roche Diagnostics GmbH, Mannheim, Germany). Levels of oestradiol, progesterone and DHEAS were measured using a competitive immunoassay on an Immulite 2000 analyser (Diagnostic Products Corporation, Los Angeles, CA, USA). Levels of SHBG, LH and prolactin were measured by an immunometric assay on an Immulite 2000 analyser. Reagents and calibrators supplied by the manufacturers were used. 17-OH-Progesterone levels were measured using radioimmunoassay technique with reagents and calibrators supplied by Orion Diagnostica (Espoo, Finland). The lower and upper reference values for women were 0.9 and $11.7 \mu \mathrm{moll}^{-1}$ for DHEAS, 0.7 and $11.0 \mathrm{nmoll}^{-1}$ for androstenedione, 0.1 and $2.9 \mathrm{nmoll}^{-1}$ for testosterone and 1.5 and $12.8 \mathrm{nmoll}^{-1}$ for $17-\mathrm{OH}$-progesterone. The lower detection limits were $0.6 \mathrm{nmoll}^{-1}$ for progesterone, $0.8 \mu \mathrm{moll}^{-1}$ for DHEAS and $0.1 \mathrm{nmoll}^{-1}$ for testosterone. The lower and upper detection limits were 0.07 and $7.34 \mathrm{nmoll}^{-1}$ for oestradiol, 3 and $180 \mathrm{nmoll}^{-1}$ for SHBG, 0.05 and $200.00 \mathrm{mIU}^{-1}$ for LH and 11 and $3180 \mathrm{mIU} \mathrm{l}^{-1}$ for prolactin. For each hormone, analyses were performed in a single kit on the same day. For girls with levels of progesterone, oestradiol or DHEAS below the detection limit, levels were set to $0.1 \mathrm{nmoll}^{-1}, 0.01 \mathrm{nmoll}^{-1}$ and $0.1 \mu \mathrm{moll}^{-1}$, respectively.

\section{Statistical analysis}

Median age at menarche for each birth size group was estimated by Kaplan-Meier survival analysis and multivariable analysis was performed using Cox regression. Differences in adolescent body size and hormone levels between groups according to birth size, and linear trends across birth size categories, were evaluated using general linear modelling. Mean values with 95\% confidence intervals (CI) within each birth size category are reported. In the hormone analyses, we used logarithmic transformation, as these variables were not normally distributed, and geometric means are therefore reported.

We evaluated potential confounding by BMI and age in adolescence, maternal age at menarche and residential area (Trondheim or Bergen). All analyses of body size and hormone levels in adolescence were adjusted for residential region and age in adolescence. In addition, we adjusted for menarcheal status (pre or post) in the analyses of adolescent body size and levels of prolactin and DHEAS. In other hormone analyses, we adjusted for time as menarche and day of menstrual cycle. All analyses were adjusted for gestational age. To minimise confounding by the relatively high prevalence of risk factors for SGA births, we compared the high-risk group $(n=195)$ and the random sample ( $n=67)$ for all variables included using general linear modelling. We also conducted stratified analyses of these groups for birth size related to age at menarche, adolescent body size and levels of prolactin and DHEAS. All statistical analyses were conducted using the statistical software SPSS for Windows, Release 13.0, Copyright $^{\circledR}$ SPSS Inc., 1989-2004 (Chicago, IL, USA).

\section{RESULTS}

At examination during adolescence (mean age 14.0 years), 199 out of 262 girls $(76.0 \%)$ had reached menarche (Table 1). For all birth size variables, except ponderal index, girls who were relatively small at birth were younger at menarche than those with larger birth size (Table 2). Median age at menarche for girls in the shortest birth length category $(<49.0 \mathrm{~cm})$ was 12.5 years $(95 \% \mathrm{CI}$, $12.26-12.74)$, compared with 13.3 years (95\% CI, $12.95-13.72)$ for the highest category $(\geqslant 51.0 \mathrm{~cm})$. Similar results were observed for birth weight, whereas the differences in age at menarche for the other birth size variables were smaller. Adjustment for potentially confounding factors did not substantially alter these results (data not shown).

We found that birth length, weight and head circumference were positively associated with adolescent height and weight (Table 2). The associations were further strengthened after adjustment for age at examination in adolescence, menarcheal status and geographical region. Comparing the longest and shortest categories at birth $(\geqslant 51 v s \leqslant 49 \mathrm{~cm})$, the longest were on average $6.2 \mathrm{~cm}$ taller $(164.6$ vs $158.4 \mathrm{~cm})$ and $4.2 \mathrm{~kg}$ heavier $(55.0$ vs $50.8 \mathrm{~kg})$ in adolescence. Girls in the heaviest birth category $(\geqslant 3700 \mathrm{~g})$ were $4.4 \mathrm{~cm}$ taller and $4.7 \mathrm{~kg}$ heavier in adolescence than those with birth weight below $3200 \mathrm{~g}$. For ponderal index, there was a negative association with adolescent height; girls who were thin at birth were on average taller in adolescence, but the association was attenuated after adjustment for age, menarcheal status and residential region. Girls in the highest category of birth weight and head circumference had higher BMI in adolescence compared with girls of average birth size $(P<0.02$, results not shown). None of the birth size variables were related to waist/hip ratio in adolescence, and skin-fold thickness at birth showed no association with any of the anthropometric variables in adolescence (data not shown). Adjustment for gestational age had no influence on the observed associations (results not shown).

A negative association between head circumference at birth and circulating level of prolactin in adolescence $(P$-trend $=0.03)$ was attenuated after adjustment for age at puberty, menarcheal status and residential region $(P$-trend $=0.12)$ (Table 3$)$. For other birth size factors, we found no relation with prolactin. There was a significant negative association between birth weight, head 
circumference and subscapular skin-fold thickness and circulating levels of DHEAS in adolescence (i.e. lower DHEAS levels with increasing size), unaffected by adjustment for the above factors. Mean (geometric) DHEAS for adolescent girls in the highest birth weight category was $1.95 \mu \mathrm{moll}^{-1}$ (95\% CI, 1.64-2.32) compared

Table I Mean values (s.d.), minimum and maximum values and number of missing values of selected variables among 262 Norwegian girls

\begin{tabular}{lccc}
\hline Variables & Mean (s.d.) & Range & Missing (n) \\
\hline At birth & & & \\
$\quad$ Birth weight $(\mathrm{g})$ & $3463(476)$ & $2420-4710$ & 0 \\
Birth length $(\mathrm{cm})$ & $50.0(1.8)$ & $42.0-55.8$ & 3 \\
Ponderal index $\left(\mathrm{g} \mathrm{cm}^{-3}\right)$ & $2.76(0.26)$ & $2.09-4.18$ & 3 \\
Head circumference $(\mathrm{cm})$ & $34.8(1.2)$ & $31.9-38.0$ & 2 \\
Skin-fold thickness $(\mathrm{mm})$ & $4.4(1.0)$ & $2.2-7.9$ & 3 \\
Gestational age (days) & $282.6(7.1)$ & $264.0-294.0$ & 0 \\
& & & \\
In adolescence & $14.0(0.7)$ & $12.7-15.5$ & 0 \\
Age (years) & $54.5(9.9)$ & $33.9-96.4$ & 2 \\
Weight (kg) & $162.9(6.8)$ & $143.0-183.5$ & 1 \\
Height (cm) & $20.5(3.0)$ & $14.3-32.0$ & 2 \\
BMI (kg/m $\left.{ }^{2}\right)$ & $0.78(0.06)$ & $0.63-1.26$ & 1 \\
Waist/hip ratio & $13.1(0.1)$ & $9.5-14.5$ & 6 \\
Age at menarche (years) ${ }^{a}$ & & & \\
& & & \\
Maternal & $13.0(1.4)$ & $10.0-17.0$ & 0 \\
Age at menarche (years) & &
\end{tabular}

with $2.28 \mu \mathrm{moll}^{-1}(95 \% \mathrm{CI}, 1.88-2.78)$ for the lowest category of birth weight.

For girls who were in the follicular phase of the menstrual cycle (Table 4), we found no evidence for any association between birth size and FTI or level of androstenedione in adolescence. For oestradiol, there was a tendency for a weak positive association with all factors of birth size, but significant only for subscapular skin-fold thickness. Adjustment for age at examination, time since menarche and region did not substantially influence these estimates, whereas adjustment for day of menstrual cycle reinforced them.

Comparing girls from the random sample with those whose mothers had higher risk of delivering an SGA child, we found no difference for any of the variables (all $P$-values $>0.1$, results not shown). Stratified analyses of these groups showed similar results as the overall analyses.

\section{DISCUSSION}

In this study of 262 girls who were followed from birth to adolescence, those whose birth weight, length and head circumference were relatively high had later age at menarche, higher weight and they were taller in adolescence than those with relatively small birth size. In relation to circulating hormone levels in adolescence, greater birth size was associated with relatively lower DHEAS levels; adolescent levels of oestradiol were weakly associated with birth size. For other hormones, we found no clear association with birth size.

Strengths of the present study include the various measures of anthropometry at birth and in adolescence, all standardized and

Table 2 Adolescent anthropometric measures and age at menarche by birth size among 262 Norwegian girls

\begin{tabular}{|c|c|c|c|c|}
\hline \multirow[b]{2}{*}{ Variables } & \multirow[b]{2}{*}{ No. of girls } & \multicolumn{2}{|c|}{$\operatorname{Mean}^{\mathrm{a}}(95 \% \mathrm{Cl})$} & \multirow{2}{*}{$\begin{array}{c}\text { Median }(95 \% \mathrm{Cl}) \\
\text { Age at menarche (years) }\end{array}$} \\
\hline & & Height (cm) & Weight (kg) & \\
\hline \multicolumn{5}{|l|}{ Birth length $(\mathrm{cm})$} \\
\hline$<49.0$ & 84 & | $58.4(\mid 57.0-159.7)$ & $50.8(48.6-53.0)$ & $12.50(12.26-12.74)$ \\
\hline $49.0-51.0$ & 84 & $160.8(159.5-162.1)$ & $51.7(49.6-53.8)$ & $13.08(12.94-13.22)$ \\
\hline$\geqslant 51.0$ & 91 & $164.6(163.4-165.8)$ & $55.0(53.1-56.9)$ & $13.33(12.95-13.72)$ \\
\hline Trend test ${ }^{\mathrm{b}}$ & & $\beta=3.13, P<0.001$ & $\beta=2.12, P=0.003$ & $P<0.00$ \\
\hline \multicolumn{5}{|l|}{ Birth weight (g) } \\
\hline$<3200$ & 80 & $159.9(\mid 58.5-161.4)$ & $51.8(49.6-53.9)$ & $12.58(12.32-12.84)$ \\
\hline $3200-3700$ & 101 & $160.4(\mid 59.2-161.7)$ & $50.0(48.1-51.9)$ & $13.25(12.94-13.56)$ \\
\hline$\geqslant 3700$ & 81 & $164.3(162.9-165.6)$ & $56.5(54.5-58.5)$ & $13.33(12.97-13.70)$ \\
\hline Trend test $^{\mathrm{b}}$ & & $\beta=2.16, P<0.001$ & $\beta=2.37, P=0.001$ & $P=0.00$ \\
\hline \multicolumn{5}{|c|}{ Ponderal index $\left(\mathrm{g} \mathrm{cm}^{-3}\right)$} \\
\hline$<2.63$ & 83 & $162.4(160.9-163.8)$ & $52.7(50.5-54.8)$ & $12.83(12.53-13.14)$ \\
\hline \multicolumn{5}{|c|}{ Head circumference $(\mathrm{cm})$} \\
\hline$<34.2$ & 86 & $160.5(\mid 59.0-161.9)$ & $51.9(49.8-54.0)$ & $12.83(12.42-13.25)$ \\
\hline $34.2-35.4$ & 92 & $160.8(159.5-162.1)$ & $51.0(49.0-52.9)$ & $13.42(|3.03-| 3.8 \mid)$ \\
\hline$\geqslant 35.4$ & 82 & $163.4(162.0-164.8)$ & $55.2(53.2-57.3)$ & $13.17(|2.62-13.7|)$ \\
\hline Trend test ${ }^{b}$ & & $\beta=1.45, P=0.003$ & $\beta=1.66, P=0.020$ & $P=0.003$ \\
\hline \multicolumn{5}{|c|}{ Skin-fold thickness (mm) } \\
\hline$<3.8$ & 88 & $161.5(160.0-162.9)$ & $52.2(50.1-54.4)$ & $12.83(12.53-13.13)$ \\
\hline $3.8-4.8$ & 88 & $161.3(159.9-162.7)$ & $52.5(50.4-54.5)$ & $12.92(12.46-13.37)$ \\
\hline$\geqslant 4.8$ & 83 & $161.9(160.4-163.3)$ & $53.2(51.1-55.3)$ & $13.50(13.07-13.93)$ \\
\hline Trend test $^{\mathrm{b}}$ & & $\beta=0.18, P=0.72$ & $\beta=0.50, P=0.49$ & $P=0.001$ \\
\hline
\end{tabular}

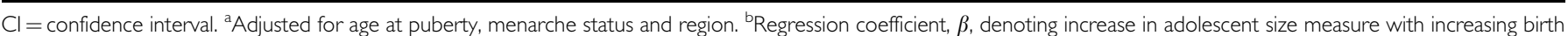
size category and corresponding $P$-value. 
Table 3 Adolescent hormone levels by birth size among 262 Norwegian girls

Geometric mean ${ }^{\mathrm{a}}(95 \% \mathrm{Cl})$

\begin{tabular}{|c|c|c|c|}
\hline Variables & $\begin{array}{l}\text { No. of } \\
\text { girls }\end{array}$ & Prolactin $\left(\mathrm{mlUl}^{-1}\right)$ & DHEAS $\left(\mu \mathrm{moll}^{-1}\right)$ \\
\hline \multicolumn{4}{|l|}{ Birth length $(\mathrm{cm})$} \\
\hline$<49.0$ & 84 & $179.9(162.1-199.6)$ & $2.28(1.88-2.78)$ \\
\hline $49.0-51.0$ & 84 & 206.1 (186.9-227.3) & $2.09(1.73-2.51)$ \\
\hline$\geqslant 51.0$ & 91 & $176.8(161.1-193.9)$ & $1.95(1.64-2.32)$ \\
\hline Trend test ${ }^{b}$ & & $e^{\beta}=0.99, P=0.74$ & $e^{\beta}=0.92, P=0.21$ \\
\hline \multicolumn{4}{|l|}{ Birth weight (g) } \\
\hline$<3200$ & 80 & I84.6 (165.7-205.6) & $2.51(2.06-3.05)$ \\
\hline $3200-3700$ & 101 & $188.7(171.8-207.3)$ & $2.08(1.75-2.46)$ \\
\hline$\geqslant 3700$ & 81 & $186.6(168.6-206.5)$ & $1.83(1.52-2.20)$ \\
\hline Trend test ${ }^{\mathrm{b}}$ & & $e^{\beta}=1.01, P=0.88$ & $e^{\beta}=0.85, P=0.015$ \\
\hline \multicolumn{4}{|c|}{ Ponderal index $\left(\mathrm{g} \mathrm{cm}^{-3}\right)$} \\
\hline$<2.63$ & 83 & $180.5(163.3-199.6)$ & $2.25(|.86-2.7|)$ \\
\hline $2.63-2.85$ & 93 & $197.6(179.8-217.2)$ & $2.16(1.81-2.58)$ \\
\hline$\geqslant 2.85$ & 83 & $181.7(164.1-201.2)$ & $1.84(1.52-2.23)$ \\
\hline Trend test ${ }^{\mathrm{b}}$ & & $\mathrm{e}^{\beta}=1.00, P=0.90$ & $e^{\beta}=0.91, P=0.13$ \\
\hline \multicolumn{4}{|c|}{ Head circumference $(\mathrm{cm})$} \\
\hline$<34.2$ & 86 & $195.5(176.2-216.9)$ & $2.47(2.03-2.99)$ \\
\hline $34.2-35.4$ & 92 & $188.4(171.5-207.1)$ & $2.03(1.70-2.42)$ \\
\hline$\geqslant 35.4$ & 82 & $175.7(159.3-193.9)$ & $1.92(1.60-2.30)$ \\
\hline Trend test ${ }^{\mathrm{b}}$ & & $\mathrm{e}^{\beta}=0.95, P=0.12$ & $e^{\beta}=0.88, P=0.047$ \\
\hline \multicolumn{4}{|c|}{ Skin-fold thickness (mm) } \\
\hline$<3.8$ & 88 & $194.7(175.6-215.9)$ & $2.4 \mid(2.00-2.91)$ \\
\hline $3.8-4.8$ & 88 & $181.8(164.7-200.6)$ & $2.19(1.83-2.62)$ \\
\hline$\geqslant 4.8$ & 83 & $185.5(167.2-205.8)$ & $1.73(1.43-2.09)$ \\
\hline Trend test ${ }^{\mathrm{b}}$ & & $e^{\beta}=0.98, P=0.48$ & $e^{\beta}=0.85, P=0.012$ \\
\hline
\end{tabular}

$\mathrm{Cl}=$ confidence interval; DHEAS = dehydroepiandrosterone sulphate. ${ }^{\text {aAdjusted for }}$ age at puberty, menarche status and region. ${ }^{b} e^{\beta} \times 100 \%$ equals percent change in hormone levels with increasing birth size category and corresponding $P$-value.

conducted by trained personnel, and the opportunity to adjust for potential confounders such as maternal age at menarche and cyclic variation of hormone levels. Girls who had reached menarche were examined shortly after their first menstrual period, reducing possible recall bias. The modest number of participants is a limitation of the study. For hormone analyses among girls who were in the follicular phase of the menstrual cycle, this reduced the precision of the results.

Our results support the previously reported positive associations of birth size (either birth weight or length), with age at menarche (Adair, 2001; Sloboda et al, 2007) and adolescent weight and height (Pietiläinen et al, 2001; Romundstad et al, 2003), and indicate that the associations may also extend to additional measures of birth size such as head circumference and skin-fold thickness.

Previous studies indicate that SGA children have higher levels of DHEAS before adrenarche (Dahlgren et al, 1998), during adolescence (Ibanez et al, 1999) and in early adulthood (Szathmari et al, 2001). An inverse relation of birth size with adrenal androgen levels in 8-year-old children has also been found for children of normal birth size (Ong et al, 2004). In a recent study of hormone levels in premenopausal women, there was a suggestive inverse association of birth weight with DHEAS (Tworoger et al, 2006), with which our adolescent DHEAS findings accord. Furthermore, it strengthens the evidence that it is valid for all birth size, and not only for SGA children.

Circulating levels of DHEAS increase during foetal life, but decline rapidly after birth and remain low during early childhood, gradually increasing from about the age of 6 years (adrenarche) through puberty and reaching a peak in early adult life, followed by a continuous decline with age (Auchus and Rainey, 2004). Dehydroepiandrosterone sulphate can be converted both to more potent androgens and to oestrogens (Ibanez et al, 2000; Nicolas Diaz-Chico et al, 2007), but its physiological role is unclear and has been hypothesised to depend on the hormonal milieu (Ebeling and Koivisto, 1994). The physiological triggers of adrenarche and adrenal androgen production are unknown, although there are indications that ACTH, insulin, IGF-I and leptin may be implicated (Ibanez et al, 2000).

Our findings could be interpreted both as further indications of the earlier maturation previously reported in children of small birth size and as a potentially lifelong influence of developmental plasticity on adrenal androgen production. The increase in concentration of DHEAS parallels the increase in skeletal age through puberty (Ibanez et al, 2000). Thus, adrenal androgen production may contribute to the relation between birth size and adolescent height, as small birth size is associated with both higher DHEAS levels and a lower adolescent and final height.

Oestrogens are believed to be involved in BC development, both prenatally (Trichopoulos, 1990) and later in life (ESHRE Capri Workshop Group, 2004). We observed a weak tendency for a positive association between birth size and adolescent oestradiol level. In two previous studies, both of which controlled for cyclic variation, positive associations of premenopausal oestradiol levels with ponderal index at birth (Jasienska et al, 2006) and birth weight (Tworoger et al, 2006) were reported. If this relation is true, it may be in accord with the positive association of birth size with $\mathrm{BC}$ risk observed in many studies.

Longitudinal growth in childhood may be positively associated with subsequent BC risk (De Stavola et al, 2004), and the association may be independent of birth weight (Ahlgren et al, 2004; dos Santos Silva et al, 2004). High childhood growth rate is also associated with earlier age at menarche (Sloboda et al, 2007), and childhood growth patterns influence the association between birth size and age at menarche (Adair, 2001; dos Santos Silva et al, 2002). A large population-based study from Denmark (Ahlgren et al, 2004) found no effect of age at menarche on BC risk after adjustment for childhood growth patterns.

There are only weak indications that the inverse relation of birth size with adrenal androgen production in childhood and adolescence continues into adulthood (Szathmari et al, 2001; Tworoger et al, 2006). However, should it do so, this would be in conflict with the association between $\mathrm{BC}$ risk and the levels of adrenal androgens in adulthood (Kaaks et al, 2005a,b), as a smaller birth size is associated with reduced risk. As for age at menarche, opposing influences of birth size and childhood growth, weight gain and overweight have also been reported for adrenal androgen production in children (Ong et al, 2004), indicating that the combined pattern of prenatal and postnatal growth may define the subsequent risk profile.

In conclusion, relatively low birth size was associated with earlier age at menarche and larger body size in adolescence, but negatively related to adolescent DHEAS level. The results demonstrate a link between prenatal factors and subsequent growth and development.

\section{ACKNOWLEDGEMENTS}

The original study was initiated by Professor Leiv S Bakketeig. We are indebted to the mothers and their daughters who participated in this study. We thank the US National Institute of Child Health and Human Development (NICHD contract nos. 1-HD-4-2803 and 1-HD-1-3127) for supporting the baseline study and the Norwegian Research Council for supporting the follow-up study. 
Geometric mean ${ }^{\mathrm{b}}(95 \% \mathrm{Cl})$

\begin{tabular}{|c|c|c|c|c|}
\hline Variables & No. of girls & Free testosterone index & Androstenedione $\left(\mathrm{nmol}^{-1}\right)$ & Estradiol $\left(\mathrm{nmoll}^{-1}\right)$ \\
\hline \multicolumn{5}{|l|}{ Birth length $(\mathrm{cm})$} \\
\hline$<49.0$ & 26 & $2.16(1.61-2.90)$ & $8.0(7.1-9.1)$ & $0.08(0.05-0.12)$ \\
\hline $49.0-51.0$ & 17 & $2.17(1.50-3.13)$ & $8.2(7.1-9.6)$ & $0.10(0.06-0.17)$ \\
\hline Trend test ${ }^{c}$ & & $\mathrm{e}^{\beta}=1.00, P=0.98$ & $e^{\beta}=1.01, P=0.81$ & $e^{\beta}=1.24, P=0.17$ \\
\hline \multicolumn{5}{|l|}{ Birth weight (g) } \\
\hline Trend test ${ }^{c}$ & & $\mathrm{e}^{\beta}=0.98, P=0.90$ & $e^{\beta}=1.03, P=0.54$ & $e^{\beta}=1.28, P=0.14$ \\
\hline \multicolumn{5}{|c|}{ Ponderal index $\left(\mathrm{g} \mathrm{cm}^{-3}\right)$} \\
\hline$<2.63$ & 24 & $2.04(1.53-2.72)$ & $8.2(7.2-9.2)$ & $0.08(0.05-0.13)$ \\
\hline $2.63-2.85$ & 18 & $2.63(1.84-3.77)$ & $7.8(6.7-9.1)$ & $0.10(0.06-0.17)$ \\
\hline$\geqslant 2.85$ & 20 & $1.98(1.42-2.75)$ & $8.4(7.3-9.6)$ & $0.11(0.07-0.18)$ \\
\hline \multicolumn{5}{|c|}{ Head circumference $(\mathrm{cm})$} \\
\hline$\geqslant 35.4$ & 14 & $2.12(1.44-3.12)$ & $8.8(7.5-10.3)$ & $0.10(0.06-0.17)$ \\
\hline Trend test ${ }^{c}$ & & $e^{\beta}=1.03, P=0.78$ & $e^{\beta}=1.06, P=0.23$ & $e^{\beta}=1.01, P=0.94$ \\
\hline \multicolumn{5}{|c|}{ Skin-fold thickness (mm) } \\
\hline$<3.8$ & 25 & $2.19(|.64-2.9|)$ & $8.2(7.2-9.2)$ & $0.07(0.05-0.11)$ \\
\hline $3.8-4.8$ & 21 & $1.62(1.16-2.27)$ & $7.4(6.4-8.5)$ & $0.11(0.07-0.17)$ \\
\hline$\geqslant 4.8$ & 14 & $2.99(2.02-4.44)$ & $9.2(7.7-10.8)$ & $0.14(0.08-0.25)$ \\
\hline Trend test ${ }^{c}$ & & $e^{\beta}=1.13, P=0.33$ & $e^{\beta}=1.05, P=0.40$ & $e^{\beta}=1.43, P=0.049$ \\
\hline
\end{tabular}

$\mathrm{Cl}=$ confidence interval. ${ }^{\mathrm{a} G i r l s}$ who were measured between day I and day 12 of their menstrual cycle and who had $\mathrm{LH}<10 \mathrm{UI}^{-1}, 17-\mathrm{OH}$-progesterone $<10 \mathrm{nmol} \mathrm{I}^{-1}$ and progesterone $<5 \mathrm{nmoll}^{-1}$. ${ }^{b}$ Adjusted for age at puberty, time since menarche, day of menstrual cycle and district. ${ }^{c} e^{\beta} \times 100 \%$ equals percent change in hormone levels with increasing birth size category and corresponding $P$-value.

\section{REFERENCES}

Adair LS (2001) Size at birth predicts age at menarche. Pediatrics 107: e59 Ahlgren M, Melbye M, Wohlfahrt J, Sørensen T (2004) Growth patterns and the risk of breast cancer in women. $N$ Engl J Med 351: 1619-1626

Auchus RJ, Rainey WE (2004) Adrenarche - physiology, biochemistry and human disease. Clin Endocrinol 60: 288-296

Bakketeig LS, Jacobsen G, Hoffman HJ, Lindmark G, Bergsjø P, Molne K, Rødsten J (1993) Pre-pregnancy risk factors of small-for-gestational age births among parous women in Scandinavia. Acta Obstet Gynecol Scand 72: $273-279$

Dahlgren J, Boguszewski M, Rosberg S, Albertsson-Wikland K (1998) Adrenal steroid hormones in short children born small for gestational age. Clin Endocrinol 49: 353-361

De Stavola BL, dos Santos Silva I, McCormack V, Hardy RJ, Kuh DJ, Wadsworth MEJ (2004) Childhood growth and breast cancer. Am J Epidemiol 159: 671-682

dos Santos Silva I, De Stavola BL, Hardy RJ, Kuh DJ, McCormack VA, Wadsworth MEJ (2004) Is the association of birth weight with premenopausal breast cancer risk mediated through childhood growth? Br J Cancer 91: 519-524

dos Santos Silva I, De Stavola BL, Mann V, Kuh D, Hardy R, Wadsworth MEJ (2002) Prenatal factors, childhood growth trajectories and age at menarche. Int J Epidemiol 31: 405-412

Ebeling P, Koivisto VA (1994) Physiological importance of dehydroepiandrosterone. Lancet 343: 1479-1481

ESHRE Capri Workshop Group (2004) Hormones and breast cancer. Human Reprod Update 10: 281-293

Ibanez L, Dimartino-Nardi J, Potau N, Saenger P (2000) Premature adrenarche - normal variant or forerunner of adult disease? Endocr Rev 21: $671-696$

Ibanez L, Potau N, Marcos MV, de Zegher F (1999) Exaggerated adrenarche and hyperinsulinism in adolescent girls born small for gestational age. J Clin Endocrinol Metab 84: 4739-4741
Jasienska G, Ziomkiewicz A, Lipson SF, Thune I, Ellison PT (2006) High ponderal index at birth predicts high estradiol levels in adult women. Am J Hum Biol 18: 133 - 140

Kaaks R, Berrino F, Key T, Rinaldi S, Dossus L, Biessy C, Secreto G, Amiano P, Bingham S, Boeing $\mathrm{H}$, Bueno de Mesquita HB, Chang-Claude J, Clavel-Chapelon F, Fournier A, van Gils $\mathrm{CH}$, Gonzalez CA, Gurrea AB, Critselis E, Khaw KT, Krogh V, Lahmann PH, Nagel G, Olsen A, Onland-Moret NC, Overvad K, Palli D, Panico S, Peeters P, Quirós JR, Roddam A, Thiebaut A, Tjønneland A, Chirlaque MD, Trichopoulou A, Trichopoulos D, Tumino R, Vineis P, Norat T, Ferrari P, Slimani N, Riboli E (2005a) Serum sex steroids in premenopausal women and breast cancer risk within the European Prospective Investigation into Cancer and Nutrition (EPIC). J Natl Cancer Inst 97: 755-765

Kaaks R, Rinaldi S, Key TJ, Berrino F, Peeters PH, Biessy C, Dossus L, Lukanova A, Bingham S, Khaw KT, Allen NE, Bueno-de-Mesquita $\mathrm{HB}$, van Gils $\mathrm{CH}$, Grobbee D, Boeing $\mathrm{H}$, Lahmann PH, Nagel G, Chang-Claude J, Clavel-Chapelon F, Fournier A, Thiébaut A, González CA, Quirós JR, Tormo MJ, Ardanaz E, Amiano P, Krogh V, Palli D, Panico S, Tumino R, Vineis P, Trichopoulou A, Kalapothaki V, Trichopoulos D, Ferrari P, Norat T, Saracci R, Riboli E (2005b) Postmenopausal serum androgens, estrogens and breast cancer risk: the European prospective investigation into cancer and nutrition. Endocr Relat Cancer 12: $1071-1082$

Loos RJF, Beunen G, Fagard R, Derom C, Vlietinck R (2002) Birth weight and body composition in young women: a prospective twin study. Am J Clin Nutr 75: 676-682

Michels KB, Willett WC (2004) Breast cancer - early life matters. N Engl J Med 351: $1679-1681$

Nicolas Diaz-Chico B, Rodriguez FG, Gonzalez A, Ramírez R, Bilbao C, Cabrera de León A, Aguirre Jaime A, Chirino R, Navarro D, Díaz-Chico 
JC (2007) Androgens and androgen receptors in breast cancer. J Steroid Biochem Mol Biol 105: 1-15

Okasha M, McCarron P, Gunnell D, Smith GD (2003) Exposures in childhood, adolescence and early adulthood and breast cancer risk: a systematic review of the literature. Breast Cancer Res Treat 78: 223-276

Ong KK, Potau N, Petry CJ, Jones R, Ness AR, Honour JW, de Zegher F, Ibáñez L, Dunger DB (2004) Opposing influences of prenatal and postnatal weight gain on adrenarche in normal boys and girls. J Clin Endocrinol Metab 89: 2647-2651

Pietiläinen KH, Kaprio J, Räsänen M, Winter T, Rissanen A, Rose RJ (2001) Tracking of body size from birth to late adolescence: contributions of birth length, birth weight, duration of gestation, parent's body size, and twinship. Am J Epidemiol 154: 21-29

Romundstad PR, Vatten LJ, Nilsen TIL, Holmen TL, Hsieh CC, Trichopoulos D, Stuver SO. Birth size in relation to age at menarche and adolescent body size: implications for breast cancer risk. Int J Cancer 2003; 105: $400-403$

Sloboda DM, Hart R, Doherty DA, Pennell CE, Hickey M (2007) Age at menarche: influences of prenatal and postnatal growth. J Clin Endocrinol Metab 92: 46-50

Szathmari M, Vasarhelyi B, Tulassay T (2001) Effect of low birth weight on adrenal steroids and carbohydrate metabolism in early adulthood. Horm Res 55: $172-178$

Trichopoulos D (1990) Does breast cancer originate in utero? Lancet 335: 939-940

Tworoger SS, Eliassen AH, Missmer SA, Baer H, Rich-Edwards J, Michels KB, Barbieri RL, Dowsett M, Hankinson SE (2006) Birthweight and body size throughout life in relation to sex hormones and prolactin concentration in premenopausal women. Cancer Epidemiol Biomarkers Prev 15: 2494-2501 